\section{Case Reports in Ophthalmology}

Case Rep Ophthalmol 2020;11:561-573

DOI: 10.1159/000510500

Published online: October 30, 2020

(C) 2020 The Author(s)

Published by S. Karger AG, Basel

www.karger.com/cop

This article is licensed under the Creative Commons Attribution-NonCommercial 4.0 International License (CC BY-NC) (http://www.karger.com/Services/OpenAccessLicense). Usage and distribution for commercial purposes requires written permission.

\title{
A Case of Bilateral Endogenous Candida dubliniensis Endophthalmitis Treated with Aggressive Local and Systemic Therapy
}

\author{
Kamal Kishore ${ }^{a, b}$ Daniel S. McGowan ${ }^{b} \quad$ Tulika Chatterjee $^{c, d}$ \\ Bahareh Hassanzadeh ${ }^{e}$ \\ allinois Retina and Eye Associates, Peoria, IL, USA; ${ }^{b}$ Department of Surgery, University of \\ Illinois College of Medicine, Peoria, IL, USA; 'Department of Internal Medicine, UIC-Peoria \\ Campus, Peoria, IL, USA; dDepartment of Internal Medicine, OSF St Francis Medical \\ Center, Peoria, IL, USA; ellinois Neurological Institute, Peoria, IL, USA
}

\section{Keywords}

Candida dubliniensis $\cdot$ Endophthalmitis · Voriconazole $\cdot$ Amphotericin B $\cdot$ Pars plana vitrectomy · Intravitreal injections

\begin{abstract}
Candida dubliniensis is an emerging pathogen implicated in a variety of infections in immunocompromised hosts. A 79-year-old male with autoimmune pancytopenia on chronic oral steroid therapy was admitted for suspected sepsis and started on empirical antibiotics and micafungin. He developed floaters and decreased vision while on this regimen and was diagnosed with bilateral candida endophthalmitis. Blood cultures grew C. dubliniensis. Intravenous therapy was switched to voriconazole and amphotericin B. He also received aggressive intravitreal antifungal therapy consisting of $100 \mu \mathrm{g} / 0.1 \mathrm{~mL}$ voriconazole (4 OD, 3 OS) and $5 \mu \mathrm{g} / 0.1$
\end{abstract}




\section{Case Reports in Ophthalmology}

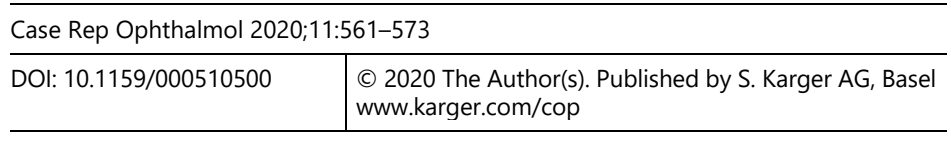

Kishore et al.: Candida dubliniensis Endophthalmitis

$\mathrm{mL}$ amphotericin $\mathrm{B}(3 \mathrm{OD}, 1 \mathrm{OS})$ over 2 weeks that resulted in local control of infection. The right eye developed a retinal detachment 1 month after initial presentation that was repaired by 25-gauge pars plana vitrectomy, scleral buckle, laser and silicone oil. At the 15-month follow-up exam, subsequent to silicone oil removal, membrane peel and cataract surgery, OD visual acuity had improved to 20/80. OS was phakic and 20/25. Aggressive intravitreal antifungal therapy combined with intravenous therapy may control endophthalmitis and avoid the risks associated with pars plana vitrectomy during acute infection.

(C) 2020 The Author(s)

Published by S. Karger AG, Basel

\section{Introduction}

Endogenous endophthalmitis (EE), also known as metastatic endophthalmitis, results from hematogenous spread of microorganisms from a distant focus. EE accounts for 3-5\% of all cases of endophthalmitis [1]. Immunocompromised status, chronic illness, diabetes, indwelling intravenous line, systemic corticosteroids, systemic malignancy and peripheral hyperalimentation are major risk factors for EE. Candida albicans is the most common cause of EE in the West [2]. Ocular candidiasis (chorioretinitis with or without endophthalmitis) occurs in $0.9-44.6 \%$ of patients with candidemia, and routine dilated fundus examination of all patients with candidemia is currently recommended $[3,4]$.

Candida dubliniensis, a newly characterized species of Candida exhibiting a high prevalence of resistance to the azole group of antifungal agents, including fluconazole, is a rare cause of EE with only 11 reported cases in seven publications [5-11]. We present a case of an immunocompromised, elderly male patient who developed bilateral endogenous $C$. dubliniensis endophthalmitis in the setting of pancytopenia and candidemia.

\section{Case Report}

A 79-year-old male with a history of autoimmune pancytopenia on $80 \mathrm{mg}$ oral prednisone per day was admitted to the hospital for workup of fever and suspected sepsis. He was empirically started on intravenous cefepime, vancomycin and micafungin. The patient developed floaters in the right eye on day 2 which worsened over the next 2 days along with rapid decrease in vision. The blood culture grew $C$. dubliniensis on day 3. Ophthalmic evaluation on day 4 showed visual acuity of 20/200 in the right eye and 20/25 in the left. External and anterior segment examinations were unremarkable except for mild cataract. The intraocular pressures were normal OU. Dilated fundus examination of the right eye showed marked vitreous exudates and two prominent areas of chorioretinitis, one in the inferotemporal quadrant (Fig. 1) and another at the inferonasal periphery. In addition, there were several small foci of chorioretinitis. The left eye showed two foci of chorioretinitis, one superonasal to the fovea and the other inferotemporal to the macula. The inferotemporal focus was larger, measuring about $1 / 2$ disk diameter and showed extension of exudates through the internal limiting membrane (Fig. 2). He was diagnosed with bilateral $C$. dubliniensis endophthalmitis in view of positive blood culture of the same organism. 


\section{Case Reports in Ophthalmology}

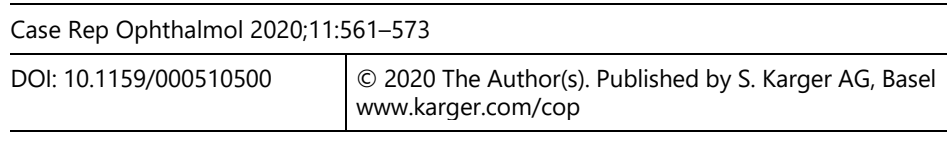

Kishore et al.: Candida dubliniensis Endophthalmitis

Vancomycin, cefepime and micafungin were stopped on day 3 and i.v. amphotericin B and voriconazole were started. After 6 days of i.v. amphotericin B and voriconazole, intravenous antifungal therapy was switched to fluconazole for the next 6 days, followed by oral fluconazole for 6 weeks, per recommendations of the infectious disease department.

After obtaining informed consent, off-label intravitreal voriconazole $100 \mu \mathrm{g} / 0.1 \mathrm{~mL}$ was administered to the right eye on days 6, 8, 10 and 11, and intravitreal amphotericin B $5 \mu \mathrm{g} / 0.1$ $\mathrm{mL}$ on days 9,12 and 19. The left eye received intravitreal voriconazole on days 6,8 and 10, and intravitreal amphotericin B on day 9. Transesophageal echocardiogram was normal without any evidence of endocarditis. Repeat blood cultures 4 days after initial positive blood culture were negative. Sensitivity results from the initial blood culture showed sensitivity to amphotericin B, caspofungin, fluconazole, micafungin, voriconazole and other antifungal agents (Table 1).

The right eye showed gradual resolution of vitreous exudates. On day 24 , lesions at the inferotemporal and inferonasal periphery had well-defined margins and the appearance of subretinal abscesses (Fig. 3,4). The visual acuity was 20/200. The left eye lesions showed complete resolution of chorioretinitis and vitreous exudates while maintaining visual acuity of $20 / 25$ (Fig. 5).

The patient returned 10 days later (day 34) with a 2-day history of nasal visual field defect affecting central vision due to macula-off temporal retinal detachment caused by formation of a retinal break over the inferotemporal chorioretinal abscess. His visual acuity had decreased to hand motions only. A combined vitrectomy buckle procedure was performed 2 days later. After thorough vitrectomy, fluid air exchange was performed through the pre-existing retinal break in the inferotemporal quadrant. The inferonasal abscess was drained with a soft-tip extrusion needle under air (online suppl. Video 1; for all online suppl. material, see www.karger.com/doi/10.1159/000510500) and resulting retinal break was surrounded with laser. No laser was done around the break in the inferotemporal quadrant because of necrotic retina around it. Silicone oil (1,000 centistokes) was used for internal tamponade.

The retina was successfully re-attached. The patient underwent cataract surgery 3 months after retinal detachment surgery with implantation of a one-piece acrylic intraocular lens in the capsular bag. A prominent epiretinal membrane formed over the macula over the next few months (Fig. 6). Silicone oil removal and removal of the epimacular membrane was performed 1 year after initial presentation (online suppl. Video 2). Three months after silicone oil removal, his visual acuity had improved to 20/80 with an attached retina (Fig. 7).

\section{Discussion}

C. dubliniensis is a newly characterized opportunistic pathogen. First isolated in 1995 by Sullivan et al. from the oral cavities of HIV-positive patients, the species was named dubliniensis after the city of Dublin where it was first identified. Since then, $C$. dubliniensis has been isolated in multiple countries. $C$. dubliniensis differs from the more common $C$. albicans by its inability to grow at $42{ }^{\circ} \mathrm{C}$, formation of dark green colonies on CHROMagar ${ }^{\mathrm{TM}}$ (CHROMagar, Paris, France), inability to express beta-glucosidase activity on multilocular enzyme electrophoresis, inability to assimilate xylose or alpha methyl D glucoside, and DNA finger printing [12]. 


\section{Case Reports in Ophthalmology}

\begin{tabular}{l|l}
\hline Case Rep Ophthalmol 2020;11:561-573 \\
\hline DOI: 10.1159/000510500 & $\begin{array}{l}\text { ( ) 2020 The Author(s). Published by S. Karger AG, Basel } \\
\text { www.karger.com/cop }\end{array}$ \\
\hline
\end{tabular}

Kishore et al.: Candida dubliniensis Endophthalmitis

Unlike $C$. albicans, $C$. dubliniensis is rarely found in the microflora of normal healthy persons and is isolated in only about $2 \%$ cases of candidemia, compared to $65 \%$ for $C$. albicans [12]. C. dubliniensis demonstrates reduced susceptibility to azole drugs, such as fluconazole, due to overexpression of transporters such as mdr1p [13]. It causes a variety of infections from mucocutaneous candidiasis to invasive disease both in immunocompetent and immunocompromised patients. However, most patients with $C$. dubliniensis infection are immune suppressed, have liver disease or give history of substance abuse [14].

In candidemia patients, the rate of developing ocular involvement (chorioretinitis with or without vitritis) ranges from 0.9 to $44.6 \%$ [3], prompting the recommendation from the Infectious Diseases Society of America (IDSA) for dilated fundus examination of all non-neutropenic patients with candidemia [4]. Systemic therapy might be adequate to treat patients with chorioretinitis, but those with vitritis also need intravitreal therapy or vitrectomy combined with intravitreal antifungal agents [4]. At this time, there is no evidence of superiority of pars plana vitrectomy over intravitreal injections alone. Although vitrectomy has theoretical advantage of reducing the fungal load, it can be difficult in patients with pre-existing cataract and can result in iatrogenic retinal breaks particularly in eyes with necrotic chorioretinitis lesions and attached posterior hyaloid. Vitrectomy has an additional drawback of reducing the half-life of almost all intravitreal administered medications by about half [15]. Despite treatment, the prognosis of candida endophthalmitis as opposed to chorioretinitis is poor according to a recent review particularly for those treated with vitrectomy, although this may be due to more severe disease in patients undergoing vitrectomy [16].

Intravitreal voriconazole has recently gained popularity for fungal endophthalmitis. However, it has a short half-life of $2.5 \mathrm{~h}$. Assuming $4 \mathrm{~mL}$ volume of an average vitreous cavity, 100 $\mu \mathrm{g}$ of intravitreal voriconazole will have $25 \mu \mathrm{g} / \mathrm{mL}$ concentration in the vitreous cavity immediately after intravitreal injection, which will decrease to below $0.008 \mu \mathrm{g} / \mathrm{mL}$ after 8 half-lives,

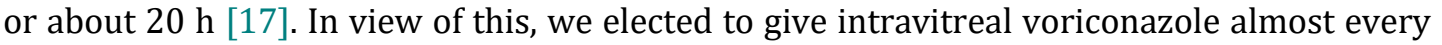
36-48 $\mathrm{h}$ for a total of four injections to the right eye and three to the less severely affected left eye.

The minimum inhibitory concentration for amphotericin B was $0.5 \mu \mathrm{g} / \mathrm{mL}$. Intravitreal amphotericin B is expected to have $1.25 \mu \mathrm{g} / \mathrm{mL}$ concentration after intravitreal injection of $5 \mu$ g. Considering the half-life of intravitreal amphotericin B to be 8.9 days [18], an injection of amphotericin B can be expected to stay therapeutic for about 1 week. We gave a total of three amphotericin B injections to the right eye and one to the left on different days than those when he received intravitreal voriconazole. This approach resulted in good control of local disease. Daily intravitreal voriconazole and alternate day intravitreal amphotericin B combination has been previously used successfully for endophthalmitis caused by filamentous fungi [19], and recently for coccidioidal endophthalmitis [20].

Although inferonasal subretinal abscess was drained during the vitrectomy procedure for retinal detachment, no additional intravitreal antifungal agents were administered. Previous reports have shown that administration of intravitreal agents may not be necessary after internal drainage of subretinal abscess [21].

To the best of our knowledge, there are only 11 previously reported cases of $C$. dubliniensis endophthalmitis in the literature till date (Table 2). Most were immune suppressed, gave history of intravenous drug use or had liver disease. Only two eyes had bilateral involvement, and only one had documented candidemia. 


\section{Case Reports in Ophthalmology}

The emergence of nonalbicans Candida species as increasingly frequent pathogens has led to the recommendation from IDSA that patients with candidemia should receive an echinocandin initially, with de-escalation to an azole after susceptibility is confirmed [4]. However, echinocandins being large molecules do not penetrate into the vitreous nor provide protection against ocular candidiasis [16]. Our patient developed symptoms despite being on empirical echinocandin therapy.

To conclude, we presented a case of bilateral $C$. dubliniensis in an immune suppressed patient. Aggressive intravitreal therapy controlled local disease. The retinal detachment in one eye was successfully managed with vitrectomy buckle laser and silicone oil procedure followed by cataract surgery, silicone oil and epiretinal membrane removal with good results.

\section{Statement of Ethics}

All procedures were done in accordance with the tenets of Helsinki Declaration of 1964, as revised in 2013. Approval from Institutional Review Board (IRB) was not required for this retrospective study involving a single case report. Written informed consent was obtained from the patient.

\section{Conflict of Interest Statement}

The authors have no conflicts of interest to declare.

\section{Funding Sources}

No funding was received.

\section{Author Contributions}

K.K. contributed to the drafting of the manuscript, collection of data, and discussion. D.S.M. contributed to the revision, formatting, and submitting of the manuscript, and worked on the references. T.C. and B.H. contributed to the drafting of the manuscript, data collection, and critical review.

\section{References}

1 Jackson TL, Paraskevopoulos T, Georgalas I. Systematic review of 342 cases of endogenous bacterial endophthalmitis. Surv Ophthalmol. 2014 Nov-Dec;59(6):627-35.

2 Connell PP, O'Neill EC, Fabinyi D, Islam FM, Buttery R, McCombe M, et al. Endogenous endophthalmitis: 10year experience at a tertiary referral centre. Eye (Lond). 2011 Jan;25(1):66-72.

3 Vinikoor MJ, Zoghby J, Cohen KL, Tucker JD. Do all candidemic patients need an ophthalmic examination? Int J Infect Dis. 2013 Mar;17(3):e146-8. 


\section{Case Reports in Ophthalmology}

\begin{tabular}{l|l}
\hline Case Rep Ophthalmol 2020;11:561-573 \\
\hline DOI: 10.1159/000510500 & $\begin{array}{l}\text { (c) 2020 The Author(s). Published by S. Karger AG, Basel } \\
\text { www.karger.com/cop }\end{array}$ \\
\hline
\end{tabular}

Kishore et al.: Candida dubliniensis Endophthalmitis

4 Pappas PG, Kauffman CA, Andes DR, Clancy CJ, Marr KA, Ostrosky-Zeichner L, et al. Clinical Practice Guideline for the Management of Candidiasis: 2016 Update by the Infectious Diseases Society of America. Clin Infect Dis. 2016 Feb;62(4):e1-50.

5 Sedeek RW, Shah M, Gentile R, Samson CM. First Case Report of Candida Dubliniensis Endogenous Endophthalmitis. Invest Ophthalmol Vis Sci. 2008;49:952.

6 Pelegrín L, Mesquida M, Adán A, Cervera C, Bosch-Mestres J, Esteban-Redondo C, et al. Candida dubliniensis endophthalmitis in a HIV-infected intravenous drug abuser. Mycoses. 2011 Nov;54(6):e856-8.

7 Espinosa-Heidmann DG, McMillan BD, Lasala PR, Stanley J, Larzo CR. Candida dubliniensis endophthalmitis: first case in North America. Int Ophthalmol. 2012 Feb;32(1):41-5.

8 Moloney TP, Park J. Candida dubliniensis endophthalmitis: five cases over 15 years. J Ophthalmic Inflamm Infect. 2013 Nov; 3(1):66.

9 Rosenberger E, Youssef DA, Safdar S, Larzo CR, Myers J. Third case of Candida dubliniensis endogenous endophthalmitis in North America: case report and review of the literature. Int Ophthalmol. 2014 Aug;34(4):945-50.

10 McMillan BD, Miller GJ, Nguyen J. Rare case of exogenous Candida dubliniensis endophthalmitis: a case report and brief review of the literature. J Ophthalmic Inflamm Infect 2014 May; 4:11. eCollection 2014.

11 Gittins-Núñez LO, Hernández-Núñez F. [Endogenous Candida dubliniensis endophtalmitis. First case in Mexico]. Rev Med Inst Mex Seguro Soc. 2015 Jan-Feb;53(1):92-6. Spanish.

12 Sullivan DJ, Moran GP, Pinjon E, Al-Mosaid A, Stokes C, Vaughan C, et al. Comparison of the epidemiology, drug resistance mechanisms, and virulence of Candida dubliniensis and Candida albicans. FEMS Yeast Res. 2004 Jan;4(4-5):369-76.

13 Gutiérrez J, Morales P, González MA, Quindós G. Candida dubliniensis, a new fungal pathogen. J Basic Microbiol. 2002;42(3):207-27.

14 Khan Z, Ahmad S, Joseph L, Chandy R. Candida dubliniensis: an appraisal of its clinical significance as a bloodstream pathogen. PLoS One. 2012;7(3):e32952.

15 Radhika M, Mithal K, Bawdekar A, et al. Pharmacokinetics of intravitreal antibiotics in endophthalmitis. J Ophthalmic Inflamm Infect 2014;4:22. eCollection 2014.

16 Breazzano MP, Day HR Jr, Bloch KC, Tanaka S, Cherney EF, Sternberg P Jr, et al. Utility of Ophthalmologic Screening for Patients With Candida Bloodstream Infections: A Systematic Review. JAMA Ophthalmol. 2019 Jun;137(6):698-710.

17 Gao H, Pennesi ME, Shah K, Qiao X, Hariprasad SM, Mieler WF, et al. Intravitreal voriconazole: an electroretinographic and histopathologic study. Arch Ophthalmol. 2004 Nov;122(11):1687-92.

18 Wingard LB Jr, Zuravleff JJ, Doft BH, Berk L, Rinkoff J. Intraocular distribution of intravitreally administered amphotericin B in normal and vitrectomized eyes. Invest Ophthalmol Vis Sci. 1989 Oct;30(10):2184-9.

19 Mithal K, Pathengay A, Bawdekar A, Jindal A, Vira D, Relhan N, et al. Filamentous fungal endophthalmitis: results of combination therapy with intravitreal amphotericin B and voriconazole. Clin Ophthalmol. 2015 Apr;9:649-55.

20 Ahmad T, Li J, Wu F et al. Coccidioidal Endophthalmitis: Excellent Recovery of Vision with Aggressive Use of Intravitreal Antifungals and Vitrectomy. Retin Cases Brief Rep. 2020 Jun; doi: 10.1097/ICB.0000000000001022. Online ahead of print.

21 Halperin LS, Roseman RL. Successful treatment of a subretinal abscess in an intravenous drug abuser Case report. Arch Ophthalmol. 1988 Dec;106(12):1651-2. 
Case Reports in Ophthalmology

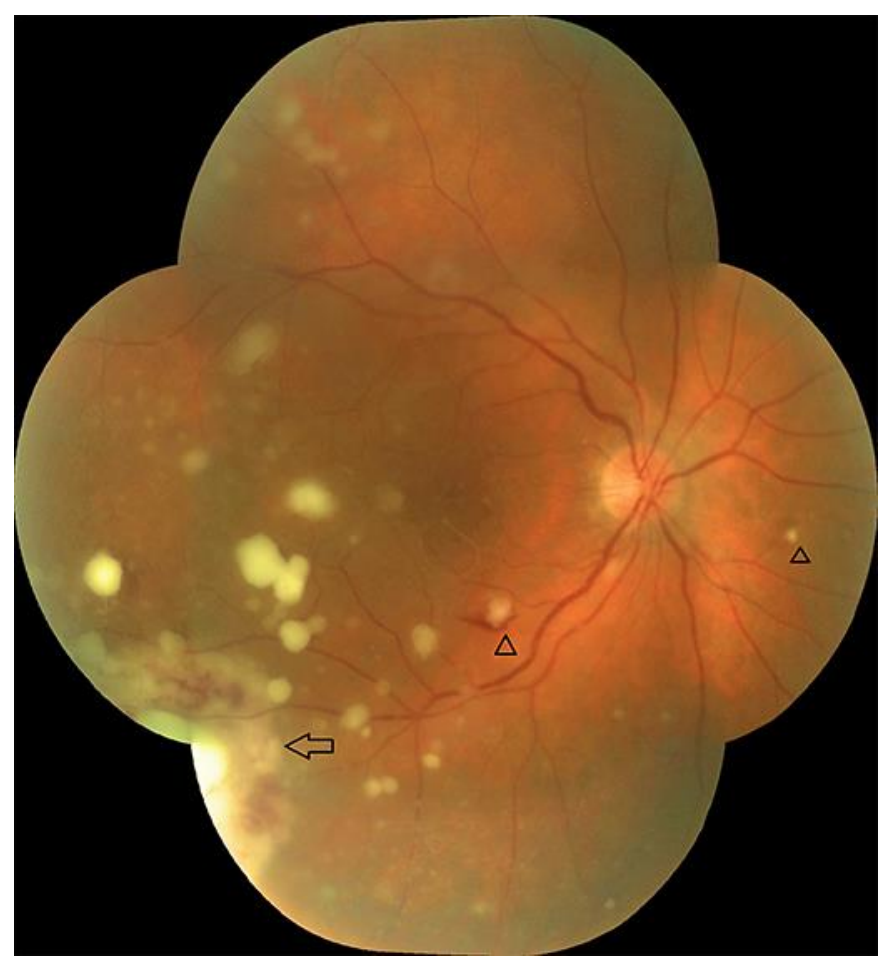

Fig. 1. Montaged fundus photograph of the right eye at presentation showing vitreous exudates (string of pearls appearance), a large area of chorioretinitis in the inferotemporal quadrant (arrow), and smaller foci of chorioretinitis (triangles). 
Case Reports in Ophthalmology

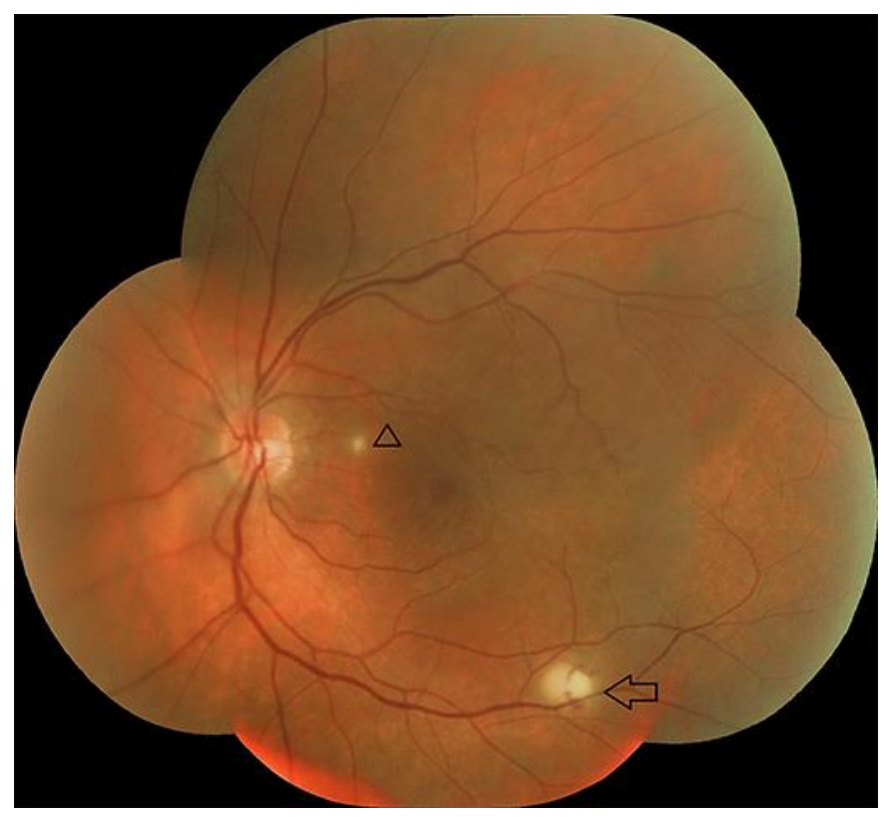

Fig. 2. Montaged fundus photograph of the left eye showing a small focus of chorioretinitis (triangle) and a larger focus with inferotemporal to fovea with extension through internal limiting membrane (arrow). 
Case Reports in Ophthalmology
Case Rep Ophthalmol 2020;11:561-573

(C) 2020 The Author(s). Published by S. Karger AG, Basel www.karger.com/cop

Kishore et al.: Candida dubliniensis Endophthalmitis

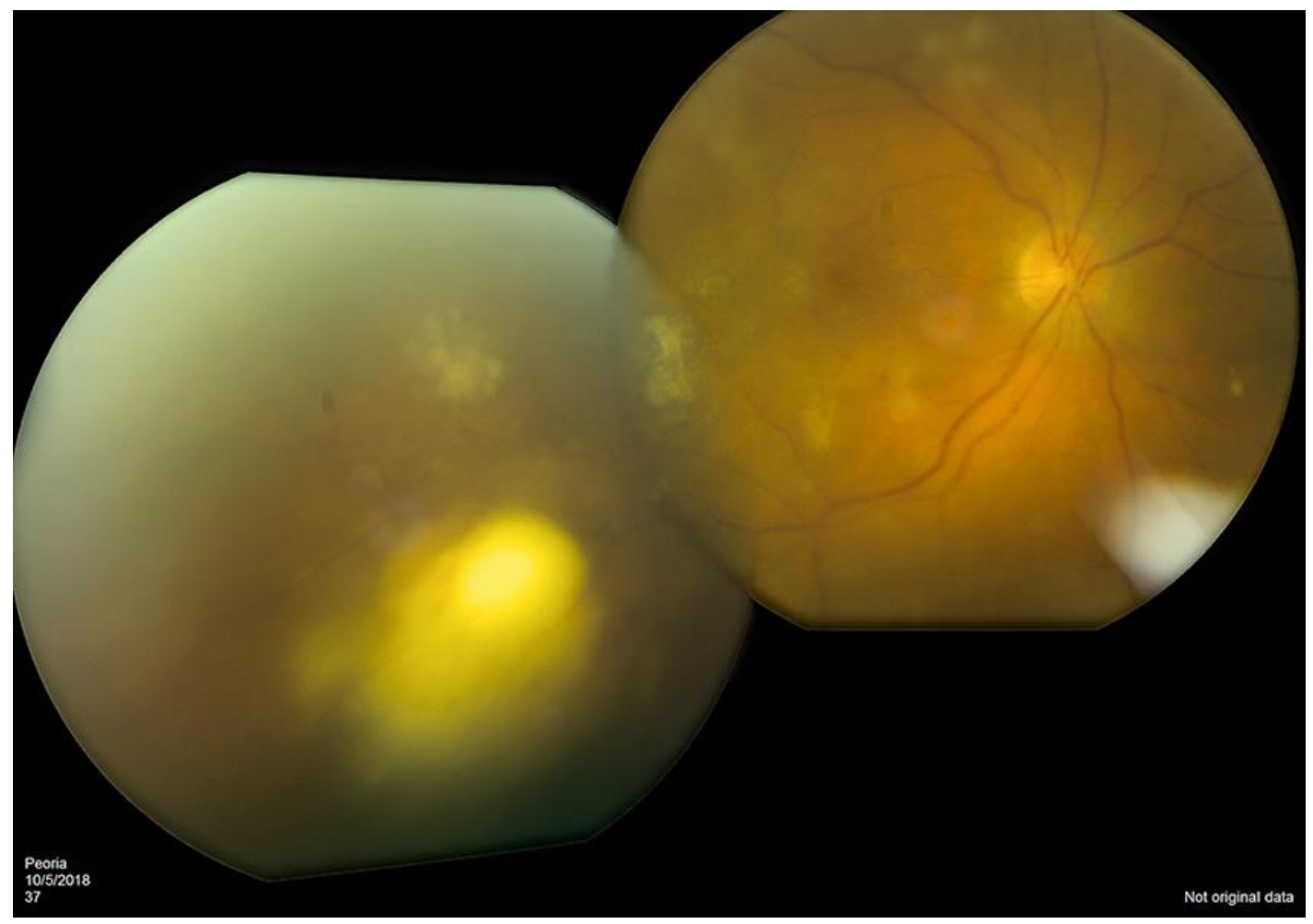

Fig. 3. Fundus photograph on day 24 showing resolution of vitreous exudates and a large chorioretinal abscess at the site of chorioretinitis shown in Figure 1. 
Case Reports in Ophthalmology www.karger.com/cop

Kishore et al.: Candida dubliniensis Endophthalmitis

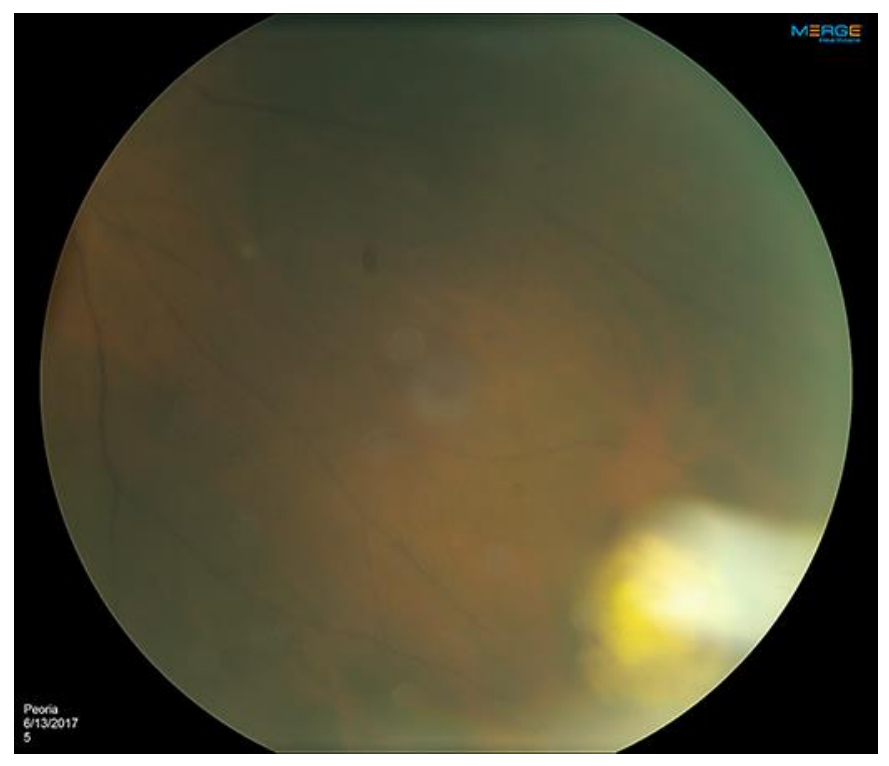

Fig. 4. Fundus photograph of the right eye on day 24 showing a choroidal abscess at the inferonasal periphery.

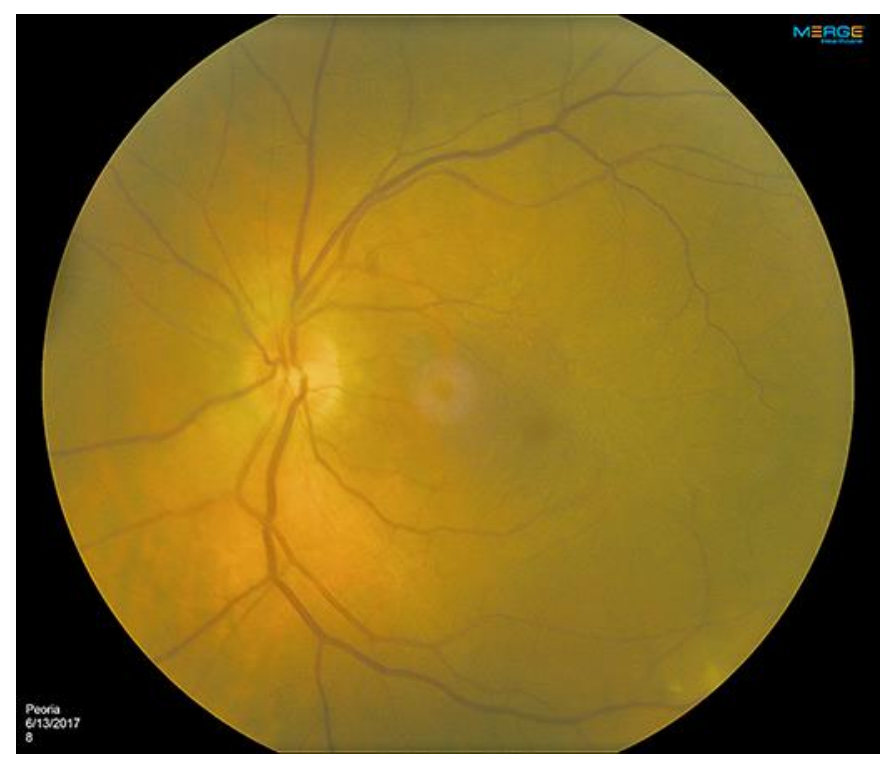

Fig. 5. Fundus photograph of the left eye on day 24 showing resolution of vitreous exudates and chorioretinitis. 
Case Reports in Ophthalmology
(C) 2020 The Author(s). Published by S. Karger AG, Basel www.karger.com/cop

Kishore et al.: Candida dubliniensis Endophthalmitis

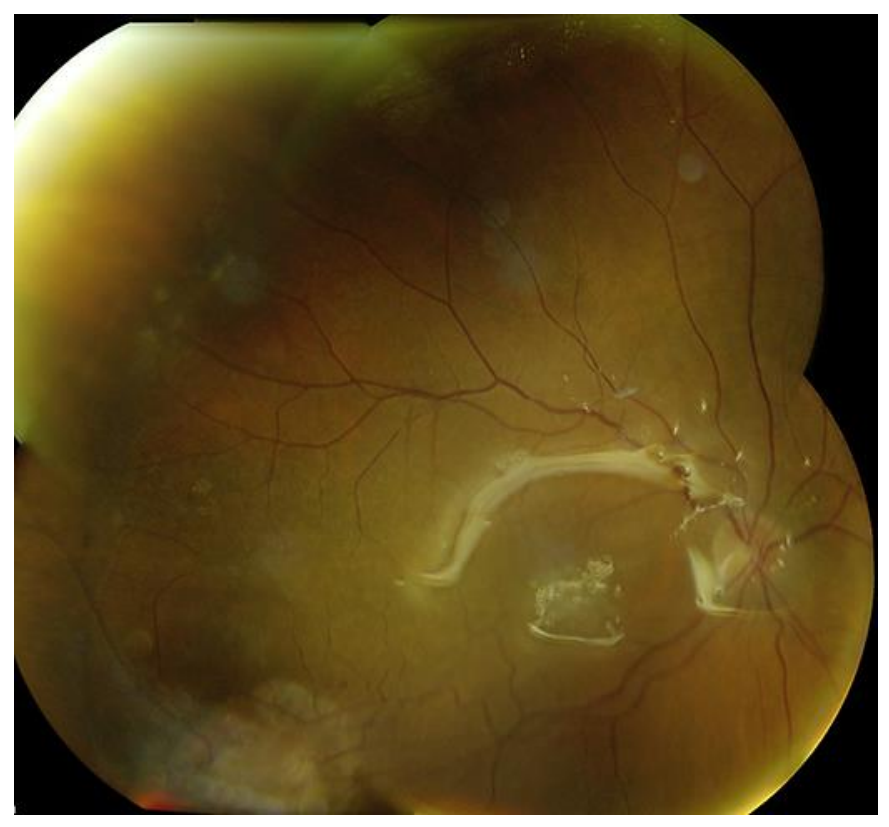

Fig. 6. Fundus photograph of the right eye 1 year after presentation, 8 months after cataract surgery, showing attached retina, a prominent epiretinal membrane over the macula and healed inferotemporal chorioretinal scar. 
Case Reports in Ophthalmology
Case Rep Ophthalmol 2020;11:561-573

DOI: $10.1159 / 000510500$ (C) 2020 www.karger.com/cop

Kishore et al.: Candida dubliniensis Endophthalmitis

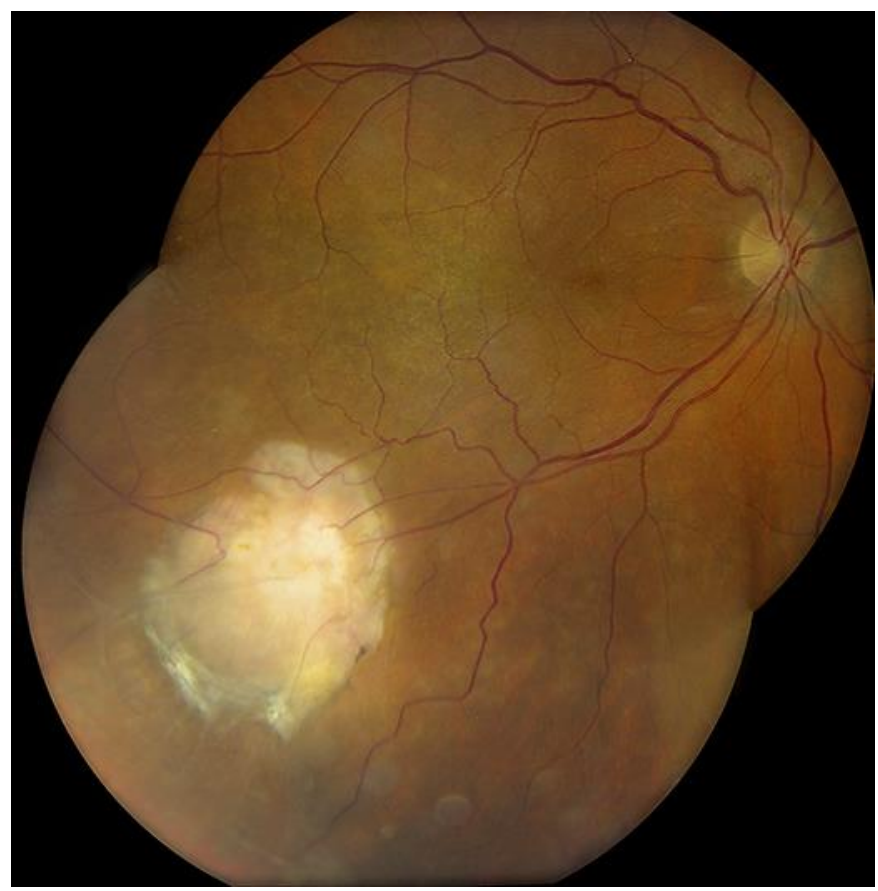

Fig. 7. Fundus photograph of the right eye 3 months after silicone oil removal and peeling of epiretinal membrane showing a normal appearing macula and inferotemporal scar.

Table 1. Sensitivity results of Candida dubliniensis from blood culture

\begin{tabular}{lc}
\hline Antifungal & MIC $(\mu \mathrm{g} / \mathrm{mL})$ \\
\hline Anidulafungin & 0.25 \\
Amphotericin B & 0.5 \\
Caspofungin & 0.12 \\
Fluconazole & 0.25 \\
5-Flucytosine & $\leq 0.06$ \\
Itraconazole & 0.06 \\
Micafungin & 0.03 \\
Posaconazole & 0.03 \\
Voriconazole & $\leq 0.008$ \\
\hline
\end{tabular}




\section{Case Reports in Ophthalmology}

\begin{tabular}{l|l}
\hline Case Rep Ophthalmol 2020;11:561-573 \\
\hline DOI: 10.1159/000510500 & $\begin{array}{l}\text { (C) 2020 The Author(s). Published by S. Karger AG, Basel } \\
\text { www.karger.com/cop }\end{array}$ \\
\hline
\end{tabular}

Kishore et al.: Candida dubliniensis Endophthalmitis

Table 2. Summary of Candida dubliniensis endophthalmitis cases

\begin{tabular}{|c|c|c|c|c|c|c|}
\hline Study, year & Age/sex & Eye & Comorbid conditions & $\begin{array}{l}\text { Presenting vi- } \\
\text { sion }\end{array}$ & Treatment & Outcome \\
\hline $\begin{array}{l}\text { Seedek } \\
{[5], 2008}\end{array}$ & $38 / \mathrm{M}$ & OD & None & $\mathrm{HM}$ & $\begin{array}{l}\text { Vitrectomy/lensectomy; IVI vancomy- } \\
\text { cin, ceftazidime, AmB; PO VCZ }\end{array}$ & Unknown \\
\hline $\begin{array}{l}\text { Pelegrin } \\
{[6], 2010}\end{array}$ & $41 / \mathrm{M}$ & OD & HIV, IVDA, Hep C, Hep B & $20 / 200$ & $\begin{array}{l}\text { PPV; IVI AmB; i.v. VCZ; PO FCZ for } 2 \\
\text { months }\end{array}$ & $20 / 60$ \\
\hline $\begin{array}{l}\text { Espinosa-Heidman } \\
\text { [7], } 2012\end{array}$ & $27 / M$ & OS & None & $20 / 400$ & $\begin{array}{l}\text { i.v. FCZ; PPV; IVI AmB; PO FCZ for } 6 \\
\text { weeks }\end{array}$ & Resolved \\
\hline $\begin{array}{l}\text { Moloney } \\
{[8], 2013}\end{array}$ & $50 / \mathrm{M}$ & OD & IVDA, Hep C & $\mathrm{CF}$ & $\begin{array}{l}\text { IVI AmB. Vitrectomy; } 2 \times \text { IVI AmB; PO } \\
\text { VCZ for } 46 \text { days }\end{array}$ & $20 / 30$ \\
\hline $\begin{array}{l}\text { Moloney } \\
{[8], 2013}\end{array}$ & $28 / \mathrm{M}$ & OD & IVDA & $20 / 200$ & $\begin{array}{l}\text { Vitrectomy and IVI VCZ; i.v. VCZ; } 3 \times \text { IVI } \\
\text { AmB; Vitrectomy, buckle and gas; PO } \\
\text { FCZ for } 42 \text { days }\end{array}$ & $\mathrm{I} 20 / 60$ \\
\hline $\begin{array}{l}\text { Moloney } \\
{[8], 2013}\end{array}$ & $34 / \mathrm{M}$ & OD & IVDA, Hep C, Endocarditis & $\mathrm{HM}$ & $\begin{array}{l}\text { i.v. FCZ; IVI AmB; Vitrectomy; PO VCZ } \\
\text { for } 35 \text { days; Vitrectomy, buckle and } \\
\text { gas }\end{array}$ & HM \\
\hline $\begin{array}{l}\text { Moloney } \\
{[8], 2013}\end{array}$ & $55 / \mathrm{M}$ & $\mathrm{OU}$ & Hep C, Liver cirrhosis & $\begin{array}{l}\text { OD } 20 / 200 \\
\text { OS } 20 / 200\end{array}$ & $\begin{array}{l}\text { i.v. FCZ; Vitrectomy OD; } 10 \times \text { IVI VCZ } \\
\text { OD; } 4 \times \text { IVI VCZ OS; Vitrectomy OS; PO } \\
\text { FCZ for } 42 \text { days }\end{array}$ & $20 / 60 \mathrm{OU}$ \\
\hline $\begin{array}{l}\text { Moloney } \\
{[8], 2013}\end{array}$ & $21 / \mathrm{F}$ & OS & IVDA, Hep C & $20 / 200$ & $\begin{array}{l}\text { i.v. VCZ, IVI AmB; } 8 \times \text { IVI VCZ; Vitrec- } \\
\text { tomy; PO FCZ for } 36 \text { days }\end{array}$ & $20 / 30$ \\
\hline $\begin{array}{l}\text { Rosenberger } \\
{[9], 2014}\end{array}$ & $31 / \mathrm{M}$ & OS & IVDA, endocarditis, Hep C & $20 / 400$ & $\begin{array}{l}\text { PO FCZ; Switched to i.v. AmB for } 6 \\
\text { weeks }\end{array}$ & $\begin{array}{l}\text { Resolved, VA } \\
20 / 25\end{array}$ \\
\hline $\begin{array}{l}\text { McMillan } \\
{[10], 2014}\end{array}$ & $41 / \mathrm{M}$ & OS & $\begin{array}{l}\text { Hep C, Hep B, CE two days } \\
\text { prior to onset (exogenous) }\end{array}$ & NLP & $\begin{array}{l}\text { PPV; IVI vancomycin, ceftazidime, } \\
\text { AmB } \\
\text { PO FCZ for } 4 \text { weeks }\end{array}$ & Enucleation \\
\hline $\begin{array}{l}\text { Gittins-Nunez } \\
{[11], 2015}\end{array}$ & $62 / F$ & $\mathrm{OU}$ & $\begin{array}{l}\text { Enterocutaneous fistula, Par- } \\
\text { enteral nutrition }\end{array}$ & $\begin{array}{l}\text { OD HM } \\
\text { OS } 20 / 60\end{array}$ & Vitrectomy OU, IVI ×3 & $\begin{array}{l}\text { OD } 20 / 60 \\
\text { OS } 20 / 25\end{array}$ \\
\hline
\end{tabular}

IVI, intravitreal injection; AmB, amphotericin B; VCZ, voriconazole; PPV, pars plana vitrectomy; FCZ, fluconazole. 